\section{Fusion frequency as a function of number and phase of binocular stimuli}

\author{
MILTON FISHER and MARCEL KINSBOURNE \\ Duke University, Durham, North Carolina 27710
}

The relation of fusion hertz to the number of pulses in a train was explored under three conditions: monoptically, dichoptically inphase, and dichoptically antiphase. All three conditions show an increase in fusion hertz as the number of pulses in the stimulating train increases. Over the range of pulse numbers investigated, fusion hertz varies principally with the number of pulses delivered to one eye regardless of the stimulating condition of the other eye.

Of the parameters that determine the repetition rate that yields the phenomenal experience of steady brightness, we here consider two: the number of pulses in a train and the distribution of those pulses between homologous retinal points.

The repetition rate that yields the perception of steady brightness may depend on the total number of pulses delivered (Bartley et al, 1961; Nelson et al, 1964; Mahneke, 1958). Repetition rates that generate flicker under the customary circumstances of continued stimulation may yield steady brightness when the total number of pulses is small. The frequency for fusion undergoes a negatively accelerated increment as a function of number of pulses up to about nine, when asymptote is reached (Nelson et al, 1964).

Sherrington (1904) studied the effect on perception of a binocularly viewed flickering stimulus by varying the phase relationship of the pulses to the two eyes. The antiphase condition yielded only slightly lower CFF than did the customary inphase form of presentation, although in antiphase light continuously stimulates the organism. He concluded that the "sensual reactions" of the "right and left corresponding retina-cerebral points, retain individually as regards time relations even when completely confluent by reference to visual space." In antiphase stimulation a decrement of CFF of no more than about $9 \%$ of inphase stimulation has since been confirmed repeatedly (Ireland, 1950; Baker \& Bott, 1951; Perrin, 1954; Foley \& Stager, 1965; Kinsbourne \& Coughlin, 1969).

The question arises: How do these two variables, number of pulses and phase of binoculer stimulation, interact? Do the corresponding retinal loci manifest this "temporal individuality" even for trains of pulses few in number or is the independence of the two visual analyses a feature that is established only over time?

In exploring this problem, we have controlled two aspects of the Bartley fraction of .5. Pulse frequency was continuously monitored by a eye fields were separated by a central barrier in the chamber. The counter was capable of preselecting pulse trains of from two to eight pulses. All train lengths were used at a pulse-to-cycle

DICHOPTIC

(IN PHASE)

8

4

DICHOPTIC

(ANTI PHASE)

4

2
Hewlett-Packard 5512 A electronic counter. Figure 1 illustrates the stimulus configurations used. The stimuli were circular, subtending 2.3 deg of visual angle at a luminance of $25 \mathrm{fL}$. Ss viewed the dim incandescent lamps in the chamber and, by changing accommodation, fused them into a single disk. An experimental session consisted of the presentation of pulse trains from one of the 21 randomly ordered experimental conditions (three methods of presentation by seven train lengths).

Discontinuous method of limits series in which the flash frequency was increased or decreased in discrete steps after each trial were presented to the Ss. A ready signal and a single train of pulses constituted a trial. Ten-second intervals separated the trials. Four ascending and descending series were used to calculate the mean frequency for fusion of each stimulus train in all conditions.

\section{RESULTS}

The differences between $\mathrm{Ss}$ were not significant $(t=.144$, $d f=40)$, and their data are combined in the following results. Table 1 presents the data in terms of mean fusion hertz, pulse period in milliseconds, and total duration of the pulse train in milliseconds for each stimulus condition. Figure 2 shows the relation of fusion hertz to number of pulses in three conditions.

Over the range of analysis (up to four pulses to one eye) all three conditions show a linear increase in fusion hertz $(b=5.5)$ with no significant differences between them.

In the monoptic and dichoptic inphase conditions beyond four pulses, fusion hertz continues to increase and appears to asymptote with trains of eight pulses at approximately $30 \mathrm{~Hz}$ (Fig. 3). The dichoptic antiphase

\begin{tabular}{|c|c|}
\hline $\begin{array}{l}\text { STIMULUS } \\
\text { CONOITION }\end{array}$ & $\begin{array}{l}\text { NUMBER OF PULSES } \\
\text { (TOTAL) (ONE EYE) }\end{array}$ \\
\hline
\end{tabular}

MONOPTIC 444
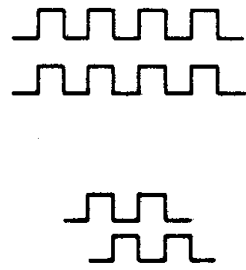

Fig. 1. Sample stimulus configurations used in the present experiment. 
Table 1

Mean Fusion Hz, Period, and Total Duration for Trains Varying in Number of Pulses from 2 to 8 . Pulse-to-cycle fraction is .5 .

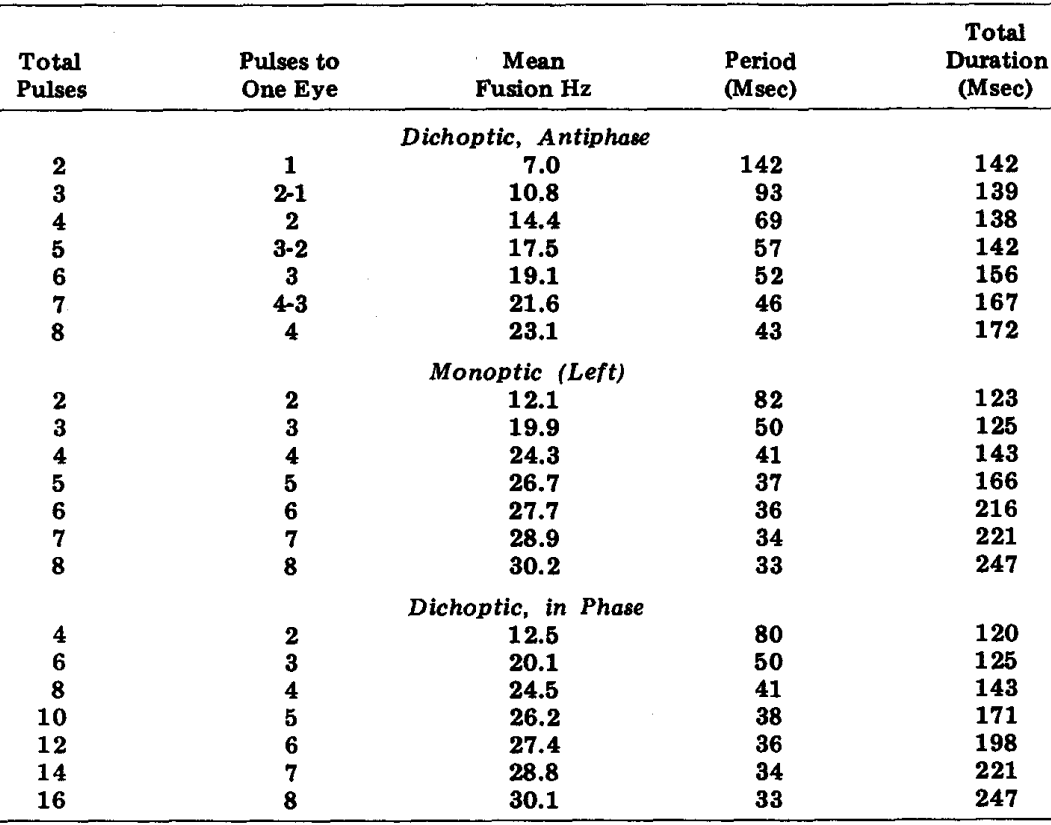

condition could not be compared with the other conditions beyond four pulses.

In the monoptic condition, our value is similar to that obtained by Bartley et al, in the PCF $1 / 8$ condition (1961). The irregularity seen by Bartley with pulse trains longer than six pulses was not evident in our results, presumably due to the controlled method of presentation.

A repeated-measures analysis of variance (Myers, 1966) which included

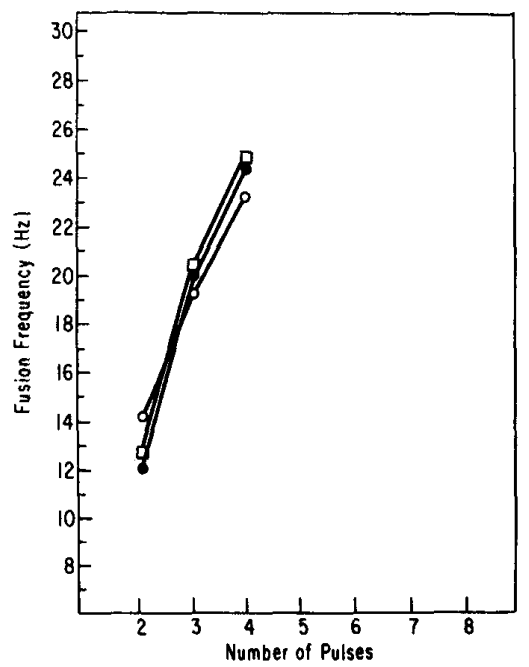

Fig. 2. Fusion hertz as a function of number of pulses in a train under three conditions: monoptic $\bullet$; dichoptic inphase $\square$; dichoptic antiphase 0 .
Ss as a factor was done on the data for the 4-, 6-, and 8-pulse dichoptic inphase and antiphase conditions. The comparison was made between an equal number of pulses delivered to one eye regardless of the stimulating conditions of the other eye. The significant component in the analysis was between number of pulses $[F(2,9)=2280, p<.01]$ and not method of delivery (monoptic, dichoptic in- or antiphase) $[F(2,9)=.125, p>.25]$. The interaction, Method of Delivery by Number of Pulses, was significant $[F(4,9)=28.25, p<.01]$. Table 2 shows the sums of squares, degrees of freedom, and mean squares in the analysis. $A$ subsequent test on individual means showed three groups of means which were separated beyond the $5 \%$ level of probability on Tukey's test. Table 3 shows the ranked means and the condition that generated them.

\section{DISCUSSION}

Under the circumstances of this experiment, in- and antiphase flicker are distinguishable at subfusion rates. Fusion hertz for equal numbers of stimuli at the two eyes is a function of the number of stimuli at one eye, independent of their phase relationship to the stimuli at the other eye. When the train consists of an odd number $(n)$ of stimuli, fusion hertz is about midway between that for $n-1$ and that for $n+1$. A form of "averaging" occurs between the two the 2-, 3-, and 4-pulse monoptic and input channels, reminiscent of that which obtains when the two eyes are exposed to fields of unequal brightness (Levelt, 1966). Our results, therefore, confirm and extend the generality of Sherrington's (1904) conclusion that the "binocular sensation attained seems combined from left and right uniocular sensations elaborated independently."

Yet, this independence of the two channels does not apply to all aspects of the phenomenal appearance of intermittent illumination. At subfusion frequencies, the two displays looked different, and there was no way of adjusting relative repetition rates such that the $S$ was in serious doubt about whether he was viewing the inphase or the antiphase display. It would appear that intermittency judgments are made prior to the confluence of input from both channels. Information relevant to the overall continuity of stimulation across channels (in antiphase) does affect the phenomenal appearance of the display.

\section{SUMMARY}

Fusion hertz for a train of pulses varies with the total number of pulses in the train presented to a single eye and is only slightly affected by their phase relationship, whether inphase or antiphase, to an equal number of stimuli to the other eye. When number of stimuli to the two eyes differ by one, the level of fusion hertz suggests that there has been "averaging" of the appearances at the two eyes. This independence of events at corresponding points in the two eyes is qualified by certain phenomenal

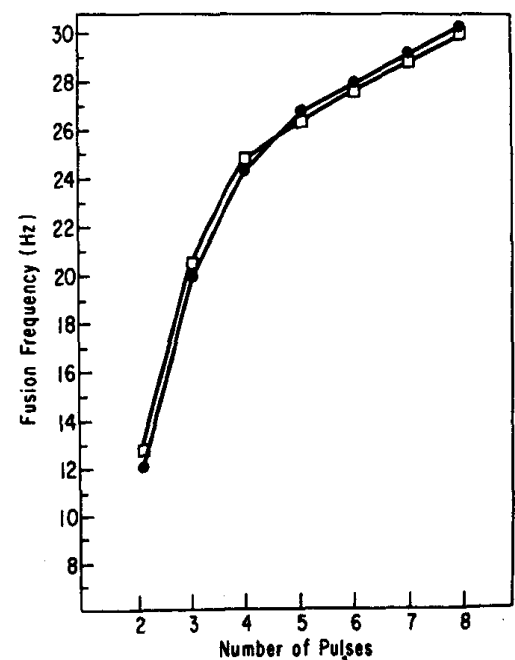

Fig. 3. Fusion hertz as a function of number of pulses in a train under two conditions: monoptic $\bullet$; dichoptic inphase $\square$. 
Table 2

Repeated Measures Analysis of Variance

\begin{tabular}{lrrr}
\hline \multicolumn{1}{c}{ Source of Variation } & SS & df & MS \\
\hline Number of Pulses & 364.86 & 2 & 182.43 \\
Presentation Condition & 0.02 & 2 & 0.01 \\
Number by Condition & 9.03 & 4 & 2.26 \\
Ss & 0.32 & 1 & 0.32 \\
Number by Ss & 0.16 & 2 & 0.08 \\
Condition by Ss & 0.14 & 2 & 0.07 \\
Number by Condition by Ss & 0.09 & 4 & 0.02 \\
\hline
\end{tabular}

Table 3

Ranked Mean Fusion Hz for Varying Pulse Conditions

\begin{tabular}{cccl}
\multicolumn{4}{c}{ Pulse Conditions } \\
\hline \multicolumn{5}{c}{$\begin{array}{c}\text { Pulse } \\
\text { Rank }\end{array}$} & Hean & $\begin{array}{c}\text { Number } \\
\text { (Total) }\end{array}$ & \multicolumn{1}{c}{ Condition } \\
\hline 1 & 12.1 & 2 & Monoptic \\
2 & 12.5 & 4 & Dichoptic Inphase \\
3 & 14.4 & 4 & Dichoptic Antiphase \\
4 & 19.1 & 6 & Dichoptic Antiphase \\
5 & 19.9 & 3 & Monoptic \\
6 & 20.1 & 6 & Dichoptic Inphase \\
7 & 23.1 & 8 & Dichoptic Antiphase \\
8 & 24.3 & 4 & Monoptic \\
9 & 24.5 & 8 & Dichoptic Inphase \\
\hline
\end{tabular}

differences between the two conditions at subfusion repetition rates.

\section{REFERENCES}

BAKER, C. H., \& BOTT, E. A. Studies on visual ficker and fusion. II. Effects of timing of visual stimuli on binocular fusion and flicker. Canadian Journal of Psychology, 1951, 5, 9-17.

Psychology, 1951, 5, 9-17.
BARTLEY, S. H., NELSÖN, T. M., RANNEY, J. E. The sensory parallel of the reorganization period in the cortical response in intermittent retinal stimulation. Joumal of Psychology, 1961, $52,137-147$.

FOLEY, P. J., \& STAGER, P. The phase differences function in binocular flicker. Canadian Journal of Psychology, 1965, 19, 47-55.
IRELAND, F. H. A comparison of critical ficker frequency under conditions of monocular and binocular stimulation. Joumal of Experimental Psychology. $1950,40,282-286$.

KINSBOUURNE, M., \& COUGHLIN, P. J. The demonstration of dichoptic flicker effects by use of polaroid. Quarterly Joumal of Experimental Psychology $1969,21,67-68$.

LEVELT, W. J. M. The alternation process in binocular rivalry. British Journal of Psychology, 1966, 57, 225-238.

MAHNEKE, A. Fusion thresholds of the human eye as measured with two or several light flashes. Acta Ophthalmology, 1958, 36, 12-18.

MYERS, J. L. Fundamentals of experimental design. Boston: Allyn \& Becon, 1966.

NELSON, T. M., BARTLEY, S. H., \& HARPER, E, S. CFF for short trains of photic stimulation having various temporal distributions and separations. Journal of Psychology, 1964, 58, 338-341.

PERRIN, $R, H$. A study in binocular flicker. Journal of the Optical Society of America, 1954, 44, 60-69.

SHERRINGTON, C. S. On binocular flicker and the condition of activity of "corresponding" retinal points. British Joumal of Psychology, 1904, 1, 26-59.

(Accepted for publication October 15, 1971.) 